\title{
INFORMAÇÃO, SISTEMA DE PREÇOS E REGULAÇÃO: UMA ANÁLISE "HETERODOXA" DAS INSTITUIÇÕES
}

\author{
Alain Herscovici *
}

\section{INTRODUÇÃO}

Este artigo propõe-se a analisar o papel dos preços na regulação de mercado. Depois de ter definido o corte teórico que permite diferenciar o mainstream e a heterodoxia, veremos, em que medida, no âmbito de uma abordagem heterodoxa, o sistema de preços não tem condições de implementar a regulação de mercado. A partir desta perspectiva, que ressalta a instabilidade intrínseca do sistema, estudaremos a natureza "imperfeita" da regulação de mercado e ressaltaremos o papel crucial que as instituições cumprem no processo de reprodução do sistema.

A existência e o funcionamento das instituições serão analisados como a resposta fornecida pelo sistema, diante de sua instabilidade intrínseca e da incapacidade, por parte do sistema de preços, em implementar um processo de regulação global. O paradoxo do capitalismo consiste no fato que o mercado não existe sem elementos extra-econômicos; em outras palavras, o mercado não constitui uma instância socialmente eficiente e autoreguladora, contrariamente ao que afirma o mainstream.

"Doutor em Economia pelas Universidade de Paris I Panthéon-Sorbonne et Amiens, coordenador do Grupo de Estudo em Macroeconomia (GREM) do Departamento de Economia da UFES e Professor do Mestrado. alhersco.vix@zaz.com.br 


\section{O CORTE TEÓRICO}

\section{MERCADO, INFORMAÇÃO E SISTEMA DE PREÇOS}

\section{As oposições mainstream $x$ heterodoxia}

a) No modelo walrasiano de equilíbrio geral, os preços transmitem, gratuitamente, para a totalidade dos agentes econômicos, a totalidade da informação espalhada no mercado. No âmbito de um processo centralizado no qual existe uma flexibilidade perfeita e instantânea dos preços, o comportamento racional dos agentes permite alcançar uma situação socialmente eficiente: o ótimo de Pareto. O mercado é "informacionalmente econômico": ${ }^{1}$ trata-se de um processo centralizado no qual os preços de equilíbrio, determinados ex-ante pelo leiloeiro, permitem alcançar, instantaneamente, uma situação na qual a oferta é igual à demanda.

Os novos clássicos analisam, a partir do instrumental metodológico neoclássico (racionalidade microeconômica, market-clearing e estabilidade do equilíbrio), situações nas quais a informação é imperfeita. As imperfeições do mercado tornam a informação um bem escasso; como tal, ela adquire um preço e passa a representar um custo para os agentes econômicos. Phelps, ${ }^{2}$ por exemplo, explica o desemprego a partir do conceito de desemprego de "busca" (a teoria do job search): os trabalhadores adquirirão informações até o custo marginal desta ser igual à sua receita marginal.

Na função de oferta de Lucas, ${ }^{3}$ os agentes econômicos confundem o aumento geral dos preços com o aumento dos preços relativos dos serviços e produtos que eles produzem. No caso de um aumento dos preços percebido como temporário, o agente aumenta sua oferta e o produto real será diferente do produto de equilíbrio. Assim, em função dessas imperfeições da informação, um choque monetário se traduz por um desvio entre o produto efetivo e o produto de equilíbrio.

1 ARROW, K. J. Limited Knowledge and Economic Analysis. American Economic Review, p. 4, Mar. 1974.

2 PHELPS, E. S. et al. Micro-economic foundations of emptoyment and inflation. Norton: [s. n.] 1970.

3 LUCAS, R.; SATGENT, T. J. Rational expectations and econometric practice. London: George Allen and Unwin, 1981. 
b) Ao contrário, a análise clássica da concorrência apresenta as seguintes características: é uma abordagem essencialmente dinâmica, à medida que estuda as modalidades de ajustamento dos preços sobre a posição definida pelos preços de produção; ela mostra como se realiza, tendencialmente, a igualação das taxas de lucro setoriais. Nessa concepção, trata se de um equilíbrio ex post ${ }^{4}$ a concorrência é um processo decentralizado a partir do qual os mercados se fecham em desequilíbrio; não existe a figura centralizadora do leiloeiro walrasiano e a oferta não é obrigatoriamente igual à demanda.

i) Essa análise, contrariamente à neoclássica, não é feita em termos de otimização microeconômica, pelo fato dos preços de mercado serem diferentes dos preços de produção e por não haver igualação intra-setorial das taxas de lucro. No que diz respeito a este último aspecto, Marx mostra que o valor individual pode ser diferente do valor de mercado e do preço de produção. ${ }^{5}$ A partir daí, é possível definir um universo econômico no qual existe incerteza e, conseqüentemente, não há como implementar um processo de otimização microeconômico. ${ }^{6}$

ii) A análise clássica permite estudar as modalidades de ajustamento tendencial dos preços de mercado sobre a posição definida pelos preços de produção. Esse equilíbrio nunca será efetivamente alcançado: a inovação tecnológica cria sempre oportunidades de lucro extra e a posição de longo prazo representada pelos preços de produção depende das flutuações de curto prazo dos preços de mercado. ${ }^{7}$ Os preços, definidos com base numa informação incompleta e

4 DUMÉNIL, G.; LÉVY, D. The dynamics of competition: a restoration of the classical analysis. Cambridge Journal of Economics, n. 11, p. 133-164, 1987.

5 MARX, K. Le Capital: critique de l'economie politique. Paris: Editions Sociales, 1976. Livro III, p. 195. Outros trabalhos ressaltam esse aspecto; ver, por exemplo: HERSCOVICI, A. Valor e preço de mercado: dinâmica concorrencial, equilíbrio "gravitacional”, regulação imperfeita. Cadernos de Economia, Ufes/Programa de PósGraduação em Economia, maio 1997; HARRIS, D. On the classical theory of competition. Journal of Economics, Cambridge, n. 12, p. 139-167, 1988.

6 DUMÉNIL; LÉVY, op. cit, p. 140.

7 A este respeito, Harris (1988) fala em “...path dependence affecting dynamic eoonomic process..." Ver, igualmente, o conceito de equilibro móvel em HERSCOVICI, op. cit. 
desigualmente distribuída entre os agentes, não permitem assegurar o processo de market-clearing. O mercado é concebido como uma instância descentralizada a partir da qual as transações se efetuam em situações de desequilíbrio. ${ }^{8}$

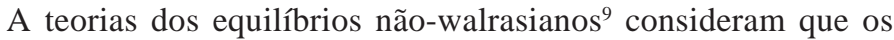
preços não se ajustam, instantaneamente, nos mercados. A partir do momento que não existe um processo centralizado de leiloeiro, os preços reais diferem dos preços de equilíbrio e as transações são efetuadas sem que haja equilíbrio entre a oferta e a demanda; em função da interdependência dos mercados, o desequilíbrio em um mercado se propaga para o conjunto da economia (spillover effect), e o sistema não gera mais uma alocação eficiente dos recursos. Os preços não têm condições de transmitir a totalidade da informação necessária ao processo de market-clearing:

i) os agentes econômicos adquirem informações baseando-se nas trocas efetivas racionadas, e não nas trocas potenciais (nocionais); conseqüentemente, o mercado não fornece um indicador que permita revelar as quantidades desejadas. ${ }^{10}$

ii) os salários dos trabalhadores se expressam sob a forma monetária e não sob a forma de demanda por bens; o mercado não fornece aos produtores os sinais que permitiriam conhecer a demanda real. ${ }^{11}$ A existência da moeda se traduz, neste sentido, pela incerteza;

iii) finalmente, o mercado não tem condições de gerar expectativas perfeitas: um aumento da poupança, por exemplo, pode significar um aumento do consumo futuro; não obstante, os produtores interpretam este fato como uma queda do consumo. ${ }^{12}$

8 DWNÉNIL; LÉVY, op. cit., p. 141.

9 Ver, por exemplo: CLOWER, R. W. The keynesian counterrevolution: a theorical appraisal. In: HAHN, F. H.; BRECHLIMGEDS, F. R. P. The theory of interest rates. [S. 1.]: Mac Millan, 1999; BÉNASSY, J. P. Macroéconomie et théorie du déséquilibre. Dunod, 1984.

10 LEIJONHUFVUD, A. Keynes and keynesians: a suggested interpretation, American Economic Review, v. 52, n. 2, 1967.

11 LEIJONHUFVUD, A. On keynesian economics and the economics of Keynes. New York: Oxford University Press, 1981.

12 BÉNASSY, op. cit., p. 193. 
iv) a informação fornecida pelo mercado é, por natureza, "imperfeita"; os ajustamentos se realizam a partir das quantidades, o que pode provocar a existência de capacidades ociosas. Em certos aspectos, essa problemática é próxima da análise clássica. Por outro lado, ela ressalta a incapacidade dos preços de assegurar uma alocação ótima dos recursos; neste sentido, trata-se de definir um universo muito mais próximo ao universo clássico que do neoclássico. ${ }^{13}$

Para os pós-keynesianos, a economia capitalista é uma economia monetária de produção: a moeda, na sua função de reserva de valor, caracteriza esse tipo de economia. As expectativas de longo prazo formuladas pelos empresários são concebidas num ambiente de incerteza; a moeda representa um meio para se prevenir contra a incerteza: sendo um ativo com liquidez imediata e tendo um poder de compra estável, ela permite diminuir a incerteza intrínseca do sistema. Numa perspectiva keynesiana, o processo de produção é um processo temporal no qual existem defasagens importantes: a decisão de produzir é baseada nas expectativas do nível da demanda e constitui uma variável ex-ante, enquanto a demanda real representa uma variável ex-post; o jogo da oferta e da demanda não é explicativo, à medida que oferta e demanda se relacionam com períodos diferentes. $\mathrm{O}$ sistema de preços não permite assegurar a coordenação de decisões individuais decentralizadas. ${ }^{14}$

i) Os gastos realizados pelos capitalistas "hoje" dependem de suas expectativas no que diz respeito à demanda "amanhã";

ii) por outro lado, existe incerteza. em relação aos preços futuros que permitiriam igualar oferta e demanda. O mercado não tem condições de fornecer as informações necessárias para determinar, "hoje", os preços futuros;

iii) os mercados são interdependentes e o desequilíbrio no mercado futuro se traduz por um desequilíbrio nos outros mercados..$^{15}$

13 HERSCOVICI, op. cit.

14 A este respeito, Carvalho fala em não-preconciliação dos planos individuais. CARVALHO, F. C. Moeda, produção e acumulação: uma perspectiva póskeynesiana. Moeda e produção: teorias comparadas, Brasília, p. 175, 1992.

15 Encontramos esta argumentação em: ARROW, op. cit., p. 8; KREGEL, J. A. Markets and institutions as features of a capitalistic production sysiem. Journal of Post-keynesian Economics/Fall, v. 3, n. 1, 1980. 


\section{As implicações em relação à natureza dos mercados: o corte} teórico

a) O conjunto das análises ligadas ao mainstream, permite definir um universo econômico no qual o mercado é concebido como uma instância socialmente eficiente. Os mercados são sempre cleared e os agentes atuam racionalmente, igualando custos e receitas marginais. Podem aparecer imperfeições da informação; nesse caso, os agentes econômicos não conseguem obter, através dos preços, a totalidade da informação disponível no mercado, o que gera desvios em relação aos resultados do modelo walrasiano. As informações adquirirão um custo; os agentes econômicos igualarão o custo marginal da informação com a receita marginal que resulta da aquisição dessa informação. Eles continuam agindo racionalmente e os mercados são sempre cleared. Este universo define-se pela ausência de incerteza, no sentido keynesiano; ele é probabilizável. O modelo das expectativas racionais é construído a partir desse princípio. Não obstante, surge o seguinte paradoxo: os agentes econômicos só poderão avaliar a pertinência econômica das diferentes informações depois de tê-las comprado. Poderão, assim, comprar informações que se revelam ser, ex-post, não pertinentes. A existência da incerteza não permite implementar um processo de maximização no que diz respeito às modalidades de aquisição da informação.

Esse universo se caracteriza, implícita ou explicitamente, pelo igual acesso à informação por parte dos agentes econômicos. Segundo Muth, as expectativas são racionais quando "... são essencialmente o mesmo que as previsões da teoria econômica relevante". ${ }^{16}$ Utilizando a informação disponível, todos os agentes conhecem perfeitamente o modelo teórico e utilizam o mesmo modelo de referência; essas hipóteses são, todavia, restritivas. As imperfeições da informação explicam os desajustamentos que aparecem a curto prazo. As análises de Lucas caracterizam-se pela percepção equivocada dos agentes econômicos: confundem o aumento geral dos preços com o preço do serviço ou do produto que eles oferecem. ${ }^{17}$ Não obstante, no

16 MUTH, J. F. Rational expectations and the theory of price movements. Econometrica, n. 29, 1961.

17 A função de oferta de Lucas é a seguinte: $y t=y^{*}+\beta\left(p t-p^{*} t\right)$, onde yt representa a oferta real em t e $\mathrm{y}^{*}$ a oferta que corresponde ao pleno emprego, pt os preços efetivos e p*t previstos para o período t; assim, se o nível real dos preços for superior ao nível previsto, os produtores interpretam isto como um aumento de seus preços relativos e a oferta real torna-se superior à oferta de equilíbrio. Ver LUCAS; SARGENT, op. cit. 
longo prazo, o equilíbrio realizado é walrasiano, a curva de oferta global sendo vertical. ${ }^{18}$ Uma melhor divulgação da informação relativa ao movimento geral dos preços deve permitir um ajustamento sobre a posição de equilíbrio

$\mathrm{O}$ conceito de custo de menu utilizado pelos novos-keynesianos consiste no fato das empresas ajustarem seus preços de forma intermitente e não contínua, ${ }^{19}$ em relação às variações da demanda; esses custos podem ser assimilados aos custos de ajustamento. Se as empresas deixam de pagar esses custos, isto se traduz por externalidades negativas no nível da sociedade. Na perspectiva novo-keynesiana, esta rigidez relativa dos preços é explicada a partir da existência de um custo relativo à produção da informação necessária para realizar essa mudança de preços, ${ }^{20}$ a qual se relaciona tanto com a demanda quanto com a oferta. Neste caso, qualquer modalidade que diminua este custo diminuirá a rigidez dos preços.

b) Em relação ao mainstream, tanto a análise clássica quanto a pós-keynesiana constituem alternativas coerentes: a partir de uma outra definição do universo econômico e de sua dinâmica, e tendo em vista a existência da incerteza, elas fornecem uma outra explicação do funcionamento do sistema. É preciso apontar as principais características desse universo.

i) Em função da existência da incerteza e da ausência de sinal no que diz respeito aos mercados futuros, os mercados não são mais equilibrados e os agentes econômicos não podem mais atuar racionalmente: quanto à decisão de investimento, Keynes deixa claro que o empresário iguala o custo marginal à receita marginal prevista. ${ }^{21} \mathrm{Se}$ a receita marginal prevista for diferente da real, as possibilidades de maximização microeconômica desaparecem.

ii) O próprio processo concorrencial existe pelo fato da informação ser, por natureza, incompleta e distribuída desigualmente entre os diferentes agentes. É possível distinguir, assim, dois tipos de incerteza: a que se explica pelo fato que não é possível prever o futuro (o caso, por exemplo, da deci-

18 Para uma apresentação detalhada, ver MANKIW, G. Macroeconomia. Rio de Janeiro: Livros Técnicos e Científicos, 1995. cap. 8 e 11.

19 Ver, por exemplo, MANKIW, op. cit., p. 220.

20 LE CACHEUX, J. Les apports de la Nouvelle École classique à 1'analyse économique. Problèmes économiques, Paris, n. 2177, 30 maio, 1990.

21 KEYNES, J. M. A teoria geral do emprego, do juro e da moeda. São Paulo: Atlas. 1990. p. 115. 
são de investimento), e a incerteza estratégica, ligada à descentralização das decisões individuais e à interdependência dos agentes. ${ }^{22}$ Nesse tipo de perspectiva, a problemática consiste, essencialmente, em assegurar a coordenação econômica de decisões interdependentes a partir de certas formas (ou combinações) institucionais que organizam a distribuição da informação entre os diferentes agentes. Essas atividades de coordenação consistem em implementar mecanismos estabilizadores afim de diminuir a incerteza e a instabilidade gerados pelo funcionamento do mercado.

iii) A construção neoclássica exclui de seu campo de investigação a concorrência: no modelo walrasiano, as taxas de lucro intra-setoriais tornam-se iguais, o que significa que o conjunto das firmas que compõem a indústria tende a adotar a mesma técnica de produção ${ }^{23}$ as firmas têm o mesmo acesso à informação tecnológica e, no nível intra-setorial, não existe lucro extra. Ao contrário, acreditamos que a concorrência explica-se pela busca desse lucro extra; no âmbito de um processo de "destruição criativa", o equilíbrio é rompido cada vez que aparece uma inovação tecnológica. O processo concorrencial explica-se pela distribuição desigual da informação entre os diferentes agentes, seja do ponto de vista do acesso à tecnologia, seja do ponto de vista das estratégias desenvolvidas pelas firmas. O processo concorrencial torna necessário um nível mínimo de informações para o conjunto dos participantes assim como uma distribuição desigual desta informação: a primeira característica permite efetivar a concorrência, enquanto a segunda explica sua dinâmica. ${ }^{24}$

iv) No âmbito de uma abordagem heterodoxa, os sinais emitidos pelo sistema de preços são, por natureza, imperfeitos e parciais: imperfeitos, pelo fato dos diferentes agentes não

82, 1972.

22 RICHARDSON, G.B. The organisation of Industry. Economic Journal,

23 HARRIS, op. cit., p. 149.

24 CHARBIT, C. La nouvelle règlementation des télécommunications en France: quel fonctionnement de marché? In: COLÓQUIO INTERNACIONAL "ECONOMIA DAS TECNOLOGIAS DA INFORMAÇÃO E DA COMUNICAÇÃO", Campinas. Paper... Campinas: [s. n.], nov. 1997. p. 10. 
terem o mesmo acesso à informação (cf. o conceito de assimetria da informação); parciais, pelo fato de serem, intrinsecamente, opacos. ${ }^{25}$

\section{O ESTATUTO TEÓRICO DOS PREÇOS: O PROBLEMA DA EXTRAÇÃO DO SINAL}

\section{A concepção marxista}

A análise das modalidades de regulação torna necessário o estudo da natureza e do papel dos preços em relação à regulação de mercado. Conceberemos, os preços de produção como preços de oferta $;{ }^{26}$ esses preços não são obrigatoriamente realizados no mercado. No nível microeconômico, o produtor acrescenta a seu custo, avaliado em preço de produção, o equivalente da taxa média de lucro. As empresas que não produzem com o custo equivalente ao custo médio da indústria não vão realizar seu preço individual, já que o mercado reconhece um preço de produção único. $O$ mark up assim determinado tem que ser concebido com uma variável definida ex-ante, e seu grau de realização depende da estrutura dos mercados. ${ }^{27}$

Por outro lado, se a demanda for superior (inferior) à oferta, o preço de mercado será superior (inferior) ao preço de produção. Nesse caso, as condições de realização serão diferentes das condições de produção. Nessa perspectiva, os preços de produção são determinados ex-ante, enquanto os preços de mercado são determinados ex-post; os preços de produção são preços previstos pelos capitalistas enquanto os preços de mercado são preços efetivamente realizados. ${ }^{28}$

25 A este respeito, ver o conceito de viscosidade dos preços em HERSCOVICI, A. Os fundamentos macroeconômicos da regulação de mercado: uma análise a partir de Marx e de Keynes. Cadernos de Economia, UFES/Progama de PósGraduação em Economia, maio 1997.

26 HERSCOVICI, A. Processo de gravitação e “revoluções do valor”: algumas observações metodológicas e epistemológicas. In: CONFERENCE OF THE INTERNATIONAL WORKING GROUP ON VALUE THEORY BOSTON, 1999. Paper... [S. 1.: s. n.], 1999.

27 POSSAS, M. L. Dinâmica da economia capitalista. Uma abordagem teórica. [S. 1.: s. n, 19-]. p. 252 e seguintes. 
Existem vários níveis de incerteza:

i) no nível microeconômico, esta incerteza provém do fato que, quando o produtor implementa o processo de produção, ele não conhece o preço de mercado: o preço de produção individual definido ex-ante, em função do diferencial de custos intra-setorial pode ser diferente do preço de produção próprio à esfera considerada;

ii) da mesma maneira, a incerteza se manifesta, no nível mesoeconômico, quando existe uma diferença entre o preço de produção e o preço de mercado;

iii) finalmente, a partir de certas condições, ela pode se propagar no nível macroeconômico e gerar uma insuficiência (ou um excesso) de demanda.

\section{A concepção keynesiana}

Encontramos uma concepção semelhante em Keynes: o preço de oferta representa um preço previsto ex-ante enquanto o preço de demanda representa um preço efetivamente realizado ex-post. ${ }^{29}$ Esta dinâmica age tanto no plano micro quanto no plano macroeconômico. Isso foi amplamente enfatizado pelos pós-keynesianos: uma vez que é preciso um certo tempo para a produção tornar-se efetiva, os preços de oferta são preços a prazo: um gasto efetuado "hoje" pelo empresário gera receitas "amanhã". ${ }^{30} \mathrm{~A}$ introdução do tempo na análise implica que esses dois preços não se igualam obrigatoriamente.

A partir disso, podemos formular as seguintes observações:

i) os preços, assim definidos, não são preços neoclássicos, na medida em que não permitem realizar, obrigatoriamente, um ajustamento otimizador nos mercados;

ii) a dinâmica e a instabilidade poderão ser explicadas a partir dos desvios entre preços ex-ante e preços ex-post.

28 HERSCOVICI, op. cit.

29 BARRÈRE, C. Hypothèses keynésiennes et dynamique dex prix. In: KEYNES aujourd'hui: théories et polìtiques. Paris: Economica, 1985. p. 394. 
É possível entender, assim, porque a incerteza constitui uma característica do universo definido pela heterodoxia; as expectativas dos diferentes agentes econômicos não são plena e automaticamente realizadas nos níveis micro, meso e macroeconômicos. Consequentemente, no nível microeconômico, é impossível maximizar uma função de lucro, ou de utilidade, à medida que os agentes econômicos raciocinam a partir de valores esperados e não de valores reais. ${ }^{31}$ A partir deste tipo de análises, não existem mercados, no sentido neoclássico, pelo fato dos agentes econômicos não terem condições de "conhecer os termos reais da troca" ${ }^{32}$ Nos níveis micro e mesoeconômicos, os mercados reais funcionam apenas a partir das expectativas dos agentes econômicos; trata-se de um tempo "expectacional" no sentido definido por Shackle; conforme veremos, mais adiante, é preciso combinar este tempo expectacional com as lógicas sociais e históricas ligadas à existência das instituições. ${ }^{33}$ Não obstante, nada indica que o funcionamento deste tipo de mercado permite alcançar um equilíbrio estável, nem gerar uma situação ótima. Na medida em que não existem razões para as expectativas dos agentes econômicos serem plenamente realizadas, os mercados não constituem "um princípio geral de equilíbrio". ${ }^{34}$

\section{REGULAÇÃO "IMPERFEITA", INSTABILIDADE MACROECONÔMICA E PAPEL DAS INSTITUIÇÕES}

\section{A ANÁLISE CLÁSSICA E MARXIANA}

\section{O processo smithiano de regulação perfeita}

No âmbito da escola "clássica" e de seus desenvolvimentos modernos, principalmente a escola neo-ricardiana, a análise é feita a partir da

30 DAVIDSON, P. Money and the real world. London: Mac Millan, 1978. 31 KREGEL, op. cit., p. 36.

32 GRELLET, G. Salaire monétaire et réparttition. In: KEYNES aujourd'hui: théories et politiques. Paris: Economica, 1985. p. 482.

33 CARVALHO, F. C. On the concept of time in Shacklean and Sraffian economics. Journal of Post-keynesian Ecanomics, Cambridge, v. 6, n. 2, Winter 1983-84.

34 DELEPLACE, G.; MAURISSON, P. Introduction, L’hétérodoxie dans la 
determinação de um centro de gravidade em direção ao qual a economia tende a convergir; o preço natural, que representa a posição de equilíbrio de longo prazo, é determinado independentemente dos movimentos de curto prarzo ligados à variação da procura e da oferta. Durante o processo de ajustamento, o preço natural, determinado a partir do valor-trabalho, e o nivel da procura permanecem constantes. A curto prazo, temos as seguintes relações:

$$
\mathrm{pm}-\mathrm{pp}=\mathrm{f}(\mathrm{eD}), \mathrm{com} \mathrm{f}^{\prime}(\mathrm{eD})>0(1)
$$

$\mathrm{pm}=$ preço de mercado

$\mathrm{pp}=$ preço de produção (preço natural em Smith e Ricardo)

$\mathrm{eD}=$ excesso inicial da demanda em relação à oferta.

A longo prazo:

$\delta(\mathrm{O})=\mathrm{eD}(2)$

com $(\mathrm{eD})=$ constante e $\mathrm{pp}=$ constante.

$\delta(\mathrm{O})=$ variação da oferta.

i) A partir desta concepção, o tempo utilizado é, por natureza, reversível, ou seja, a-histórico: o fato dos preços de produção serem constantes durante o processo de ajustamento implica que os agentes econômicos possam modificar sua atuação no curto prazo, o que não provoca modificações no longo prazo. Nesse caso, a atuação dos agentes é totalmente reversível e a mudança desta atuação não gera efeitos desestabilizadores em relação à posição de longo prazo. ${ }^{35}$ Ao contrário, Marx utiliza um tempo histórico, irreversível por natureza. Essa irreversibilidade permite dar conta da incerteza inerente à decisão econômica e explicar a dinâmica da concorrência capitalista.

ii) Essas análises descrevem um processo de regulação perfeita: a variação das quantidades ofertadas é exatamente aquela que permite, ex-post, igualar oferta e procura. Isto significa que as expectativas microecômicas foram totalmente realizadas; por exemplo, quando a demanda é superior à oferta, o lucro extra atrai novas empresas. Estas produzirão exatamente o aumento da oferta necessário para alcançar uma nova posição de equilíbrio na qual a oferta é igual à procura. Essa idéia de coordenação global do sistema é pa-

pensée économique. Cahiers d'Economie Politique, Paris, anthropos, p. 9, 1985. 
recida com os resultados da construção neoclássica. $O$ sistema dos preços fornece o sinal que permite alcançar esta posição de equilíbrio; seria assim possível assimilar o conceito de mão invisível com o de regulação perfeita.

Não obstante, essa análise é limitada pelas seguintes razões: é pouco provável que a demanda permaneça constante quando o preço realmente pago, ou seja, quando o preço de mercado aumenta; isto permite, ao contrário, prever um processo de gravitação instável. ${ }^{36}$ Por outro lado, o fato do preço de produção permanecer constante durante o processo de ajustamento implica em certas contradições. Na teoria da renda diferencial de Ricardo, o fato da demanda por trigo ser superior à oferta torna necessário o cultivo das terras de qualidade inferior; Ricardo reconhece que o valor do trigo é determinado pela quantidade de trabalho aplicada nas terras de pior qualidade. ${ }^{37} \mathrm{O}$ equilíbrio não é estático à medida que um excesso inicial de demanda provoca uma modificação do valor do trigo. Os preços de produção não permanecem constantes durante o processo de ajustamento devido à incorporação de terras de menor fertilidade. Trata-se de um equilíbrio móvel, no qual não é possível distinguir curto e longo prazos.

\section{Regulação “imperfeita” e viscosidade dos preços}

a) A regulação "perfeita" implica em alcançar uma situação na qual, tendencialmente, $\mathrm{pmi}-\mathrm{ppi}=0$. A regulação será qualificada de "imperfeita" ${ }^{38}$ se, por exemplo, a partir de uma situação inicial na qual pmi ppi $>0$, a situação final é tal que pmi - ppi < 0 . O processo de gravitação existe se (pmio - ppio $)+(d p m i / d t-d p p i / d t) \rightarrow 0$, ou seja, se $\mathrm{K}+\mathrm{dpmi} / \mathrm{dt}-\mathrm{dppi} / \mathrm{dt}=$ 0 ; nesse caso, $\mathrm{dppit} / \mathrm{dt}=\mathrm{dpmi} / \mathrm{dt}+\mathrm{K}($ pmio - ppio $=\mathrm{K}>0)$. Trata-se da estabilidade do equilíbrio macroeconômico: enquanto a regulação perfeita corresponde a um equilíbrio estável, a regulação imperfeita correspondei a um equilíbrio instável.

35 CARVALHO, op. cit., p. 275.

36 STEEDMAN, I. Natural prices, diferent pmfit rates and the classical competitive process. The Manchester School of Economics and Social Sciences, v. 2, 1984.

37 RICARDO, D. Princípios de Economia Política e Tributação. São Paulo: Abril Cultural, 1982. p. 68. 
i) se dppi/dt $=\mathrm{K}+$ dpmildt, pmi - ppi $=0$, e a regulação é perfeita e, no final do processo de ajustamento, o equilíbrio é alcançado;

ii) se dppi/dt $<\mathrm{K}+$ dpmi/dt, não há processo de gravitação à medida que pmi - ppi $>0$;

iii) se dppi/dt > K + dpmi/dt, pmi - ppi < 0; a regulação é imperfeita, pelo fato de passar de uma situação na qual pmi $>$ ppi, para uma situação na qual pmi < ppi.

(O índice $i$ representa o valor da variável no início do processo e $t$ sua variação durante o processo de ajustamento.)

b) A esse respeito, é interessante observar que os preços estabelecidos pelos mercados não constituem indicadores eficientes pelo fato deles não fornecerem o sinal adequado que permita realizar as transferências intersetoriais de capital adequadas: conforme mostra Steedman, ${ }^{39}$ em função da interdependência dos mercados, os desvios entre os preços de produção e os preços de mercado não significam, sistematicamente, um diferencial de lucro no mesmo sentido.

Esse argumento pode ser formalizado da seguinte maneira: no caso de uma economia dividida em dois setores, o setor 1 produzindo o capital constante e o 2 os bens de consumo, os lucros, nos dois setores, podem ser representados pelas seguintes equações:

$$
\left\{\begin{array}{l}
\mathrm{L} 1=(\mathrm{pm} 1-\mathrm{pp} 1)-\mathrm{x} \mathrm{C} 1-\mathrm{yV} 1(1) \\
\mathrm{L} 2=(\mathrm{pm} 2-\mathrm{pp} 2)-\mathrm{x} \mathrm{C} 2-\mathrm{yV} 2(2)
\end{array}\right.
$$

(ppi representa os preços de produção, pmi o preço de mercado, Li o lucro setorial e $\mathrm{x}$ e y os coeficientes de transformação de $\mathrm{C}$ e $\mathrm{V}$ em preços)

V2) $>0(3)$

Por exemplo, L1 > L2 $\Rightarrow$ pml- ppl - (pm2 -pp2) > x. (Cl- C2) + y. (V1-

Em termos dinâmicos, $\mathrm{pml}>\mathrm{ppl}$ tem que ser interpretado como um aumento de $\mathrm{x}$ em relação ao coeficiente de equilíbrio $\mathrm{x} *$ que corresponde ao preço de produção

As taxas de lucro setoriais são iguais a:

$$
\begin{aligned}
\mathrm{TL} 1 & =\frac{\mathrm{L} 1}{\mathrm{x} \cdot \mathrm{C} 1+\mathrm{y} \cdot \mathrm{V} 1} \\
\mathrm{TL} 2 & =\frac{\mathrm{L} 2}{\mathrm{x} \cdot \mathrm{C} 2+\mathrm{y} \cdot \mathrm{V} 2}
\end{aligned}
$$

38 Para uma análise detalhada, ver HERSCOVICI, op. cit. 


$$
\mathrm{TL} 1>\mathrm{TL} 2 \Rightarrow \frac{\mathrm{L} 1}{\mathrm{x} \cdot \mathrm{C} 1+\mathrm{y} \cdot \mathrm{V} 1}>\frac{\mathrm{L} 2}{\mathrm{x} \cdot \mathrm{C} 2+\mathrm{y} \cdot \mathrm{V} 1} \Leftrightarrow \frac{\mathrm{L} 1}{\mathrm{~L} 2}>\frac{\mathrm{x} \cdot \mathrm{C} 1+\mathrm{y} \cdot \mathrm{V} 1}{\mathrm{x} \cdot \mathrm{C} 2+\mathrm{y} \cdot \mathrm{V} 1}(6)
$$

A relação (3) representa a condição necessária e suficiente a partir da qual a um aumento do diferencial dos preços corresponde um aumento, no mesmo sentido, do diferencial das taxas de lucro setoriais; ela indica as condições, em termos de matrizes setoriais input/output, ou seja, de interdependência dos mercados, a partir das quais os preços (de mercado) constituem um sinal adequado no que diz respeito ao diferencial de lucro e às transferências intersetorais de capital correspondentes. Trata-se de comparar o diferencial de receitas, na parte esquerda, com o diferencial de custos, na parte direita. Por outro lado, pmi > ppi implica que o coeficiente de transformação é superior a seu valor de equilíbrio. Assim, o movimento dos preços de mercado, em relação aos lucros e às taxas de lucro setoriais não constitui, sempre, um indicador; existem condições restritivas, conforme ressalta a relação (3). O sistema de preços não permite realizar as transferências adequadas de capital.

\section{AS IMPLICAÇÕES MACROECONÔMICAS}

\section{Uma refutação da Lei dos mercados}

As hipóteses utilizadas são as seguintes:

- apenas os capitalistas poupam;

- a partir do momento que as variáveis são expressas em preços, $\mathrm{x}$ e y representando os coeficientes de transformação, o lucro dos capitalistas pode ser investido nos dois setores. A (B) representa a parte do lucro dos capitalistas do setor 1 (2) investida em 1 e 2.

(I) $\left\{\begin{array}{l}\mathrm{yV} 1+\mathrm{L} 1=\mathrm{xC} 2+\mathrm{I} 1+\mathrm{I} 2 \\ \mathrm{x} \mathrm{C} 2+\mathrm{L} 1 \mathrm{~A}+\mathrm{L} 2 \mathrm{~B}=\mathrm{Yv} 1+\mathrm{L} 1\end{array}\right.$

I1 representa o investimento realizado no setor 1 e I2 o investimento realizado no setor 2; a partir das hipóteses consideradas, (L1A + L2B) representa a poupança total realizada com uma parte do lucro realizado. 
Se chamamos Ig e Pg o investimento global e a poupança global, respectivamente, é possível escrever o seguinte sistema:

(II) $\left\{\begin{array}{l}\mathrm{yV} 1+\mathrm{L} 1=01=\mathrm{xC} 2+\mathrm{Ig}=\mathrm{D} 1(4) \\ \mathrm{xC} 2+\mathrm{Pg}=02=\mathrm{yV} 1+\mathrm{L} 1=\mathrm{D} 2(5)\end{array}\right.$

(Oi e Di representam, respectivamente, a oferta e a demanda setoriais e $\mathrm{Og}, \mathrm{Dg}$, Ig e $\mathrm{Pg}$, respectivamente, a oferta e a demanda, o investimento e a poupança globais)

(III) $\left\{\begin{array}{l}\left(\begin{array}{l}0 \\ 1\end{array}-\mathrm{D} 1\right)-(\mathrm{D} 2-02)=\mathrm{Pg}-\mathrm{Ig} \\ 0 \mathrm{~g}-\mathrm{D} b=\mathrm{Pg}-\mathrm{Ig}\end{array}\right.$

O sistema (III) implica que (O 1 - D 1 ) - (D2 - O2) = Pg - Ig. Se Pg for igual a Ig, o sistema (III) ressalta o fato que o excesso de oferta em um setor é automaticamente compensado por excesso de demanda em outro: $\mathrm{Ol}-\mathrm{Dl}=\mathrm{D} 2-02$, ou seja, $\mathrm{Og}=\mathrm{Dg}$. Se, por exemplo, temos O1 > D 1, o excesso de oferta no setor 1 é compensado, exatamente, pelo excesso de demanda no setor 2, e a demanda global é igual à oferta global. Assim, numa situação de equilíbrio macroeconômico em que o investimento global é igual á poupança global, a demanda global é igual à oferta global.

i) A demanda global permanece igual à oferta global. Aparece uma diferenciação das taxas médias de lucro dos dois setores, mas as transferências intersetoriais de capital devem, progressivamente, igualar as taxas de lucro setoriais como as ofertas e as demandas setoriais;

ii) conforme indicava o próprio $\mathrm{Say},{ }^{40}$ os desequilíbrios setoriais são apenas temporários, no sentido de não provocarem desequilíbrios globais.

\section{Instabilidade do equilíbrio macroeconômico e flutuações}

a) Utilizando o conceito de economia monetária de produção, e tendo em vista a incerteza a ele ligada, Keynes e os pós-keynesianos refutam a lei de Say. Enquanto os modelos keynesianos explicam essa dinâmica a partir da não-correspondência entre as variáveis ex-ante e ex-post, os modelos marxistas focalizam a análise sobre as condições de realização

39 STEEDMAN, op. cit. 
da oferta global. É possível distinguir, assim, as seguintes situações: se Pg $>\mathrm{Ig}$, então $\mathrm{Og}>\mathrm{Dg}$. Isso corresponde a uma diminuição da renda e, consequentemente, a um processo de recessão. Se, ao contrário, temos $\mathrm{Pg}<$ $\mathrm{Ig}$, isso implica em $\mathrm{Og}<\mathrm{Dg}$. Nesse caso, o aumento da renda gera um processo de expansão. Contrariamente à análise de Say, os desequilíbrios locais não desaparecem automaticamente; provocam, todavia, desequilíbrios globais e, consequentemente, flutuações econômicas.

Não existem razões objetivas para que haja um ajustamento automático entre a poupança e o investimento global pelas seguintes razões:

i) num universo onde existe uma forte incerteza, como o marxista ou o keynesiano, o investimento depende das expectativas de lucro dos empresários. Enquanto o investimento depende do lucro esperado, a poupança depende do lucro efetivamente realizado: consequentemente, a igualação entre a poupança global e o investimento global ocorre apenas no caso dos lucros realizados serem iguais aos lucros previstos. Isso ocorre apenas num universo de tipo neoclássico no qual, por definição, não existe incerteza. Nos outros casos, não existem razões para o investimento ser igual à poupança e, consequentemente, a demanda global ser igual à oferta global;

ii) a economia keynesiana e a marxista caracterizam-se pela antecedência dos gastos dos capitalistas em relação às condições de realização e de geração de renda efetiva. Nada garante que essas decisões de gastos sejam compatíveis com as condições de plena realização da oferta global. ${ }^{41} \mathrm{~A}$ oferta global é determinada ex-ante enquanto a demanda global é determinada ex-post. ${ }^{42}$

b) A igualação entre poupança e investimento relaciona-se diretamente com a natureza da moeda: se a moeda for neutra, ou seja, se ela for concebida apenas como unidade de conta, a "lei dos mercados" é verificada: os excessos de demanda são compensados pelos excessos de oferta, e o sistema alcança novamente o equilíbrio. Há neutralidade da moeda à medida que uma variação do nível geral dos preços não modifica os preços relativos. O mercado, assim definido, se autoregula; o excesso de demanda

41 KREGEL, op. cit.

42 MIGLIOLI, J. Acumulação de capital e demanda efetiva. São Paulo: Queiroz, 1981. p. 115 e seguintes. 
por bens é compensado pelo excesso de demanda por moeda e, progressivamente, oferta e demanda tornam-se iguais. ${ }^{43}$

Conforme, já observamos, a partir da lei de Say, os desequilíbrios setoriais são temporários e as transferências intersetoriais de capital anulam, progressivamente, o diferencial de taxa de lucro entre os dois setores: o sistema de preços fornece os sinais adequados para o sistema poder alcançar novamente o equilíbrio. Ao contrário, num universo heterodoxo, o ciclo e as flutuações econômicas explicam-se pelo fato do sistema de preços não fornecer tais sinais; ao contrário, ele valida decisões que afastam o sistema do equilíbrio, provocando distorções na estrutura do capital. ${ }^{44}$ Essas distorções se traduzem pela não-adequação entre a oferta e a demanda por bens de capital, ou seja, por uma regulação, por natureza, imperfeita. ${ }^{45}$

\section{O PAPEL DAS INSTITUIÇÕES}

\section{Instabilidade e instituições}

Nesse tipo de perspectiva, a problemática consiste, essencialmente, em assegurar a coordenação econômica de decisões interdependentes a partir de certas formas (ou combinações institucionais) que organizam a distribuição da informação entre os diferentes agentes. Essas atividades de coordenação consistem em implementar mecanismos estabilizadores afim de diminuir a incerteza e a instabilidade gerados pelo funcionamento do mercado. No âmbito de tal problemática, não é possível reduzir essas análises aos seus fundamentos microeconômicos:

i) as instituições constituem variáveis, por natureza, macroeconômicas e sociais;

ii) a problemática assim definida é diretamente macroeconômica pelo fato de tratar dos problemas de coordenação; a utilização do agente representativo não é possível, por definição;

40 SAY, J. B. Traité d' Économie Politique. Paris: Calman-Lévy, 1972.

43 BLAUG, M. La Pensée Economique. Origine et développement. Paris:

Economica, 1986. p. 180; neste caso, não se considera o "efeito Cantillon".

44 SOROMENHO, J. E. C. Os novos clássicos e a teoria dos ciclos de Hayek.

Revista de Economia Política, n. 3, p. 71, jul./set. 1998.

45 A este respeito, Kregel afirma que o mercado não tem condições de 
iii) finalmente, essas abordagens não consistem em utilizar o instrumental neoclássico para analisar atividades definidas como não econômicas (A economia da família, da burocracia, etc.), devido ao fato que não existem, nesse universo, racionalidade substantiva maximizadora, nem coordenação perfeita assegurada por esse mecanismo.

Os contratos em moeda (como, por exemplo, os salários) representam variáveis estabilizadoras, pelo fato de permitirem prever o nível da demanda; de uma maneira mais geral, os contatos em moeda permitem assegurar a coordenação do sistema. ${ }^{46}$ No âmbito de uma problemática semelhante, as formas institucionais definidas pela escola francesa da regulação constituem, igualmente, variáveis reguladoras. Trata-se, a partir de determinadas lógicas de regulação, de criar e divulgar informações no que concerne aos mercados futuros.

Por outro lado, um mercado não pode ser analisado independentemente das instituições sociais que o sustentam; o tipo de regulação que o caracteriza depende de certas instituições historicamente determinadas. ${ }^{47}$ À medida que o mercado não é mais considerado como uma instância universal, socialmente eficiente e auto-reguladora, ele não pode assegurar suas condições de reprodução sem a existência de certas instituições sociais. Numa perspectiva pós-keynesiana, os contratos em moeda cumprem essa função; no caso da escola francesa da regulação, diferentes formas institucionais permitem explicar a perenidade do modo de regulação. Estas cristalizam certas relações sociais, historicamente determinadas, e se relacionam diretamente com a moeda, a relação salarial, as formas de concorrência, as modalidades de inserção na economia nacional e as formas do Estado. ${ }^{48}$ As formas institucionais permitem, no âmbito de um determinado modo de regulação, conter os desequilíbrios, realizar os ajustamentos macroeconômicos e "assegurar a compatibilidade dinâmica de um conjunto de decisões decentralizadas". ${ }^{49}$

fornecer informações para orientar as decisões dos empresários (p. 44).

46 CARDIM, op. cit.

47 BARTOLI, H. L'Économie, servìce de la vie. Crise du capitalisme. Une politique de civilisation. [S. 1.]: PUG, 1996. p. 318.

48 BOYER, R. La théorie de la régulation: une analyse crítique. Paris: La DéCouvette, 1987. p. 50 e seguintes.

49 Ibid., p. 55. 


\section{A economia das "convenções"}

O problema colocado se relaciona diretamente com a possibilidade de autoregulação do mercado; o mainstream sustenta a tese da autoregulação a partir da racionalidade substantiva e da coordenação dos comportamentos individuais realizada pelo mercado. Por oposição, a heterodoxia caracterizase pela racionalidade intrinsecamente limitada, no sentido definido por Simon, e pela ausência de coordenação assegurada pelo jogo do mercado: é preciso outros elementos para permitir a reprodução do sistema, já que o sistema de preços não tem condições de cumprir esse papel. A regulação/reprodução do sistema torna necessária a existência de "arranjos institucionais", ou seja, de convenções, ${ }^{50}$ entre os diferentes agentes econômicos. Nessa perspectiva, trata-se de uma forma de institucionalismo totalmente diferentes da vertente neoclássica.

As instituições substituem, parcial ou totalmente, o sistema de preços, como instrumento de coordenação das decisões individuais. Essa incerteza já foi ressaltada no universo definido pela economia clássica e (pós) keynesiana. A teoria dos custos de transação, desenvolvida por Coase e Williamson, ${ }^{51}$ baseia-se na racionalidade limitada e na incerteza: esses custos representam, de fato, os custos que as empresas têm que assumir para poder "utilizar" o mercado. Isto pressupõe que:

i) o sistema de preços não resume a totalidade das informações necessárias à efetivação das transações: as empresas precisam assumir outros custos relativos à localização dos agentes e/ou às características dos bens;

ii) já que a racionalidade não é substantiva, existe, obrigatoriamente, "incompletude" da informação e, consequentemente, incerteza; os diferentes arranjos institucionais permitem conter esta incerteza;

iii) os custos de transação representam um meio para lidar com uma incerteza crescente, seja ela tecnológica ou ligada às modificações da demanda. Essa incerteza seria característi-

50 FAVEREAU, O. L'économie des conventions: son objet, sa contribution à la science économique. Problèmes économiques, Paris, n. 2167, 21 mars 1990. La Documemation Française.

51 A este respeito, ver a apresentação feita por PESSALI, H. F. Teoria dos custos de transação: uma avaliação crítica. In: ENCONTRO NACIONAL DE ECONOMIA, 25., 1997, Recife. Anais... Recife: Anpec, dez. 1997. v. 2. 
ca dos mercados oligopolistas com alta diferenciação dos produtos;

iv) finalmente, a "Nova Economia da Informação", representada por Stiglitz e Akerlof, ${ }^{52}$ salienta o fato que, por natureza, existe incerteza no que diz respeito ao comportamento dos agentes e à qualidade dos produtos; novamente, neste caso, o sistema de preços falha e a regulação do sistema torna necessárias certas combinações institucionais. As assimetrias da informação, que existem na maior parte dos mercados, não permitem implementar, a partir do sistema de preços, uma regulação eficiente.

\section{Instituições e processo de socialização}

Nesse sentido, as formas institucionais que definimos anteriormente representam um princípio de sociabilidade através da produção de certas normas sociais que permitem codificar e homogeneizar os comportamentos econômicos. As preferências individuais dos agentes não são definidas a priori ou exogeneizadas, mas elas se explicam a partir do contexto social. ${ }^{53}$ Um autor como Arrow chega a uma conclusão semelhante quando afirma, a respeito da racionalidade, que esta “...só faz sentido a partir do contexto social no qual ela está inserida", ${ }^{54}$ senão, os processos de aprendizagem não permitem ter acesso à totalidade da informação nem processá-la de maneira satisfatória. O Estado moderno representa uma das mediações que permite implementar a negociação entre interesses opostos.

Finalmente, a economia das convenções vai no mesmo sentido, ${ }^{55}$ ela tenta resolver os problemas ligados à heterogeneidade dos agentes, às modalidades de coordenação não mercantis que se efetuam nos mercados concretos: "a convenção é uma forma que permite coordenar os interesses

52 Ver respectivamente: STIGLITZ, J. E. Information and economic analysis: a perspective. Journal of Economic Literature, Mar. 1987; AKERLOF, G. The Market for Lemons; Qualitative Uncertainty and the Market Mechanism. Quartely Journal of Economics, 1970.

53 BOYER, op. cit., p. 57.

54 ARROW, K. Rationality of Self and Others in na Economic System. The Journal of Business, v. 59, n. 4, 1986.

55 A este respeito, ver: RALLET, A. A teoria das convenções segundo os economistas. Nexos, Salvador, v. 1, n. 2, dez. 1999; FAVEREAU, op. cit. 
contraditórios que derivam de lógicas opostas mas que têm necessidade de estarem juntas para serem satisfeitas". ${ }^{56}$

Este tipo de análise ressalta a necessidade de incorporar o Social nas modalidades concretas de funcionamento dos mercados; neste sentido, o Social pode ser concebido como um sistema de representações simbólicas que torna possível o funcionamento do jogo de mercado. Da mesma maneira, a moeda pode ser vista como uma dessas mediações simbólicas. ${ }^{57}$

$\mathrm{O}$ agente econômico não pode ser concebido, apenas, como um homos economicus que maximiza uma função de utilidade ou de lucro; ele é um sujeito social constituído cuja racionalidade e cujo sistema de valores depende de certas variáveis extra-econômicas historicamente determinadas. As concepções heterodoxas se propõem em analisar esses processos de socialização e em mostrar como esses cumprem um papel fundamental na regulação meso e macroeconômica.

A análise histórica permite formular o mesmo tipo de resultado: o sistema capitalista só conseguiu se desenvolver com a atuação do Estado moderno que permitiu unificar, homogeneizar e construir o território nacional através da criação da moeda, símbolo da soberania nacional, da unificação do direito tributário e do mercado do trabalho.

\section{CONSIDERAÇÕES FINAIS}

Esta análise permite redefinir a dicotomia entre o Econômico e o extra-econômico; à medida que o mercado não consegue assegurar suas condições de reprodução sem elementos externos, as modalidades de regulação do sistema não podem ser explicadas unicamente a partir das variáveis econômicas stricto-sensus. Segundo Théret, ${ }^{58}$ existem dois tipos de economia: o primeiro está diretamente relacionado à produção de bens materiais, cria valor e é administrado "racionalmente", ou seja, a partir de uma lógica maximizadora. Trata-se de produzir um excedente econômico, assim como de assegurar, a partir deste excedente, a reprodução ampliada do capital. O segundo tipo traduz, em termos de custos econômicos, decisões políticas: é destruidor de valor, e representa “ a dimensão material das práticas

56 RALLET, op. cit., p. 112.

57 THÉRET, B. Comment penser l'interaction entre l'économique et le politique? Pour une approche topologique des médiations monétaires et juridiques, papier présenté au Colloque UFBa/GREITD. Salvador: [s. n.], nov. 1991.

58 THÉRET, op. cit. 
sociais". ${ }^{59}$ A dinâmica de uma formação social explica-se pelo confronto, ou seja, pelo conflito que existe entre as lógicas sociais, antropológicas e culturais, por um lado, e as lógicas econômicas, por outro. ${ }^{60}$ Encontramos uma tese semelhante em certos trabalhos de História Econômica e de Sociologia Política: ${ }^{61}$ a partir do momento que o mercado não é uma instância autoregulada, as variáveis econômicas dependem de certas variáveis sociais.

No final deste trabalho, podemos observar que é possível construir uma análise "institucionalista" a partir de uma matriz teórica heterodoxa. Esta caracteriza-se por um universo econômico no qual os preços não cumprem um papel de coordenação global, o mercado não se autoregula e não há como implementar uma racionalidade de tipo neoclássica. Nessa perspectiva, o Estado é considerado como um desses mecanismos reguladores pelo fato de mediatizar e "...coordenar práticas sociais antagônicas". ${ }^{62}$

Finalmente, se o sistema econômico for concebido corno um sistema complexo, é altamente provável que ele gere uma instabilidade estrutural; nesse caso, quanto mais instável o sistema, mais importante será o papel dos diferentes mecanismos institucionais para conter essa instabilidade e assegurar, assim, a regulação do sistema. ${ }^{63}$

\section{RESUMO}

A partir da natureza da regução assegurada pelo sistema de preços e do mercado, definiremos dois universos: o do mainstream, que se caracteriza pela racionalidade substantiva dos agentes e pela eficiência do mercado e o heterodoxo, que, em função da incerteza e da ausência de regulação de mercado, ressalta a instabilidade do sistema capitalista. O papel e a natureza das instituições serão analisados no âmbito de uma abordagem heterodoxa.

Palavras-chave: regulação de mercado, instabilidade, instituições.

59 HÉRET, op. cit.

60 PASSET, R. L'Economique et le vivant. Paris: Payot, 1979. p. 51 e seguintes.

61 Ver, respectivamente: POLANYI, K. La Grande Transformation. Aux origines politiques et économiques de notre temps. Paris: Gallimard, 1983; HABERMAS, Raison et légitimité. Problèmes de légitimation dans le capitalisme avancé. Paris: Payot, 1978.

62 BAITOLI, op. cit., p. 261.

63 VERCELLI, V. Methodological foundations of macroeconomics: Keynes and Lucas. Cambridge: Cambridge University Press, 1991. p. 36 e 37. 


\begin{abstract}
Based on the nature of regulation assured by the system of prices and the market, we define two universes: the mainstream, characterised by economic agent's rationnality and market's efficiency, and the heterodoxy, which, as consequence of uncertainty and lack of market's regulation, emphasizes the instability of capitalism. The role and content of institutions will be analysed in the ambit of an heterodox approach.

Key-words: regulation, instability, institutions.
\end{abstract}

\title{
REFERÊNCIAS
}

AKERLOF, G. The Market far Lemons; Qualitative Uncertainty and the Market Mechanism. Quartely Journal of Economics, 1970.

ARROW, K. J. Limited Knowledge and Economic Analysis. American Economic Review, Mar. 1974.

Rationality of Self and Others in an Economic System, The Journal of Business, 59, n. 4, 1986.

BARRÈRE, C. Hypothèses keynésiennes et dynamique des prix. In: KEYNES aujourd'hui: théories et politiques, Paris: Economica, 1985.

BARTOLI, H. L'Économie, service de la vie. Crise du capitalisme. Une politique de civilisation. [S. 1.]: PUG, 1996.

Economie et création coltective, Paris,: Economica, 1997.

BÉNASSY, J. P. Macroéconomie et théorie du déséquilibre, Dunod, 1984.

BLAUG, M. La Pensée Economique. Origine et développement, Paris: Economica, 1985.

BOYER, R. La théorie de la régulation: une analyse critique, Paris: La Découverte, 1987.

CARVALHO, F. C. Moeda, produção e acumulação: uma perspectiva póskeynesiana. In: SILVA, M. L. F. (Org.). Moeda e produção: teorias comparadas. Brasília: UnB, 1992. p. 175.

On the concept of time in Shacklean and Sraffian economics. Journal of Postkeynesian Economics. Cambridge, v. VI, n. 2, Winter 1983-84.

CLOWER, R. W. The keynesian counterrevolution: a theorical appraisal. In: HAHN, F. H.; BRECHLIMGEDS, F. R. P. The theory of interest rates [S. 1.]: Mac Millan, 1969.

DELEPLACE G.; MAURISSON P. Introduction, L'hétérodoxie dans la pensée économique. Cahiers d'Economie Politique, Paris, anthropos, 1985.

DUMÉNIL, D. L. The dynamics of competition: a restoration of the classical analysis. 
Cambridge Journal of Economics, 1987, n. 11, p. 133-164.

FAVEREAU, O. L'économie des conventions: son objet, sa contribution à la science éconornique. Problèmes économiques, Paris, n. 2167, 21 mars 1990. La Documentation Française.

HABERMAS, J. Raison et légitimité. Problèmes de légitimation dans le capitalisme avancé. Paris: Payot, 1978.

HARRIS, D. On the classical theory of competition. Cambridge Journal of Economics, n. 12 , p. $139-167,1988$.

HERSCOVICI, A. Valor e preço de mercado: dinâmica concorrencial, equilíbrio "gravitacional" regulação "imperfeita". Cadernos de Economia, Ufes/Programa de PósGraduação em Economia, maio de 1997.

Os fundamentos macroeconômicos da regulação de mercado: uma análise a partir de Marx e de Keynes. Cadernos de Economia, Ufes/Programa de PósGraduação em Economia, maio de 1997.

Modelo de crescimento a dois setores, equilíbrio macroeconômico e instabilidade estrutural. In: ENCONTRO NACIONAL DA ANPEC, Recife, 25., 1997, Recife. Anais...

Processo de gravitação, concorrência e preço de produção: uma perspectiva dinâmica, CONFERENCE OF THE INTERNATIONAL WORKING GROUP ON VATUE THEORY, 1999, Boston. Papel... Boston: [s. n.], 1999.

HUÁSCAR, F. P. Teoria dos custos de transação: uma avaliação crítica In: ENCONTRO NACIONAL DE ECONOMIA, 1997, Recife. Anais... Recife: Anpec, 1997.

KEYNES, J. M. A teoria geral do emprego, do juro e da moeda. São Paulo: Atlas, 1990.

Keynes and keynesians: a suggested interpretation. American Economic Review, v. 52, n.2, 1967

KREGEL, A. Markets and institutions as features of a capitalistic production system. Journal of Pos- keynesian Economics/Fall, v. 3, n. 1, 1980.

LE CACHEUX, J. Les apports de la Nouvelle École classique à l'analyse économique. Problèmes économiques, Paris, 1990.

LEIJONHUFVUD, A. On keynesian economics and the economics of Keynes. New York: Oxford University Press, 1981.

LUCAS, R.; SARGENT, T. J. Rational expectations and econometric practice, London: George Allen and Unwin, 1981.

MANKIW, G. The Growth of Nation. Brooking Papers on Economics Activity, n. 1, 1995.

Macroeconomia. Rio de Janeiro: Livros Técnicos e Científicos 1995.

MARX, Karl. Le Capital. Paris: Editions Sociales, 1972.

MIGLIOLI, J. Acumulação de capital e demanda efetiva. São Paulo: Queiroz Editor, 1981.

MUTH, J. F. Rational expectations and the theory of price movements. Econometrica, n. 29, 1961.

PASSET, R. Ecanomique et le vivant. Paris: Payot, 1979. 
PHELPS, E. S. et ali. Micro-economic foundations of employment and inflation. [S. 1.]: Norton, 1970.

POLANYI, K. La Grande Transformation. Aux arigines politiques et économiques de notre temps. Paris: Gahirnard, 1983.

POSSAS, M. L. Dinâmica da economia capitalista. Uma abordagem teórica. [S. 1.: s. n., 19-].

RALLET, A. A teoria das convenções segundo os economistas. Nexos, Salvador, v. 1, n. 2, dez. 1999.

RICARDO, D. Princípios de Economia Política e Tributação. São Paulo: Abril Cultural, 1982. p. 68.

RICHARDSON, G. B. The organisation of Industry. Economic Jaurnal, n. 82, 1972.

SAY, J. B. Traité d' Économie Politique. Paris: Calman-Lévy, 1972.

SOROMENHO, J. E. C. Os novos clássicos e a teoria dos ciclos de Hayek. Revista de Economia Política, v. 3, n. 71, jul./set. 1998.

STEEDMAN, I. Natural prices, diferent profit rates and the classical competitive process. The Manchester School of Economics and Sacial Sciences, v. 2, 1984.

STIGLITZ, J. E. Information and economic analysis: a perspective. Journal of Economic Litterature, mar. 1987.

THÉRET, B. Comment penser I'interaction entre l'économique et le politique? Pour une approche tapologique des médiations monétaires et juridiques, papier présenté au Colloque UFBa/GREITD. Salvador: [s. n.], 1991.

VERCELLI, A. Methodological foundations of macroeconamics: Keynes and Lucas Cambridge: Cambridge University Press, 1991. 